\title{
Economic Enhancements to a First-Year Net Zero Energy Home Design Project
}

Prof. Andrew Lau, Pennsylvania State University, University Park

Andrew Lau is an associate professor of Engineering and coordinator of first-year seminars. He earned his B.S.M.E. from Penn State in 1977, and his M.S.M.E. from the University of Wisconsin - Madison in 1983. 


\section{Economic Enhancements to a First-Year Net Zero Energy Home Design Project}

A half-semester long project has been developed at a major large public university to introduce students to engineering design. The project focuses on the design of a net zero energy home (NZEH) by four-person teams, and was reported on at the 2012 ASEE meeting in San Antonio. This past summer, a significant effort was undertaken to include cost and engineering economics into the design. This paper begins by summarizing that earlier paper, then describes the development of the cost data and economic analysis. This is followed by some parametric studies performed by the authors, and insights into the most viable design features from an economic standpoint. The last section reports on experiences using the enhanced project in class in fall 2012. The plan is to limit each NZEH design to a fixed construction cost budget, and then to have students do tradeoff analysis considering insulation levels, number and types of windows, type of heating/cooling system, solar water heating, and perhaps most importantly, overall size of the house. Construction cost data was developed from RSMeans along with consultations with contractors and equipment suppliers. By constraining the project to be NZEH, the efficiency levels that are economically justified are measurably higher than a more typical house design where current electricity prices are the basis for energy tradeoffs. Another way of saying this is that putting in more insulation in the wall, for example, and reducing the electricity needed for heating and cooling is less expensive than purchasing a larger solar electric system to provide that electricity. Looking at the bigger picture, it is saying that if designers were to include the cost of providing renewable electricity into their designs, they would design differently and houses would use significantly less energy.

\section{Introduction}

This project is the first of two half-semester long projects that introduce first-year engineering students to engineering design in EDSGN 100, Introduction to Engineering Design. Most engineering students must take EDSGN 100, and most take it in their first year, amounting to approximately 1800 students each year. The course is three credits and meets three times a week for fifteen weeks. Each meeting is for two 50-minute periods which is twice that for a lecturebased course, reflecting the studio nature of EDSGN 100.

The first project is more structured and provides the students with an opportunity to learn and apply a design process while developing their teamwork, communication, and ethics skills. The second project is industry-sponsored and more open-ended, and typically all teams in all sections work on the same project. Students apply stakeholder needs assessment, ideation, research, analysis, testing, concept selection, detailed design, prototyping, and reporting.

In the Zero Energy Home ( $\mathrm{ZEH}$ ) project, students work in four person teams to design the home of their dreams with the main constraint being that it must produce as much energy as it uses over the course of a year. The project was piloted by Prof. Lau in spring semester 2010, and in fall semester 2010, two other faculty used it, followed by spring 2011 when two additional faculty utilized the project. The experiences and practices from these semesters was reported at the 2012 ASEE meeting in San Antonio. ${ }^{1}$ 
The project is intended to take seven to eight weeks to complete. It is also designed to utilize team-based active learning in the classroom. Most importantly, it serves as a rich context for learning and applying engineering design principles and selected analytical concepts, most notably conservation of energy and system analysis. Students also learn about sustainability, cradle-to-cradle design, and ecological footprint.

While the project is successful in many respects, it is disappointing in that students tend to neglect the importance and necessity of adjusting norms and values. Ironically, the insight gained into energy efficiency and solar technologies furthers their technological optimism that sustainability can be achieved via technology alone. While technological innovation and advancement is certainly necessary to move toward sustainability, we also feel strongly that it cannot be achieved solely by technology.

For example, students, and people in general in the U.S., tend to build bigger and bigger houses, with more and more electrical devices in them, and farther from their day-to-day needs. Even though each individual house may have increased insulation, better windows, and high efficiency heating and cooling systems, the total energy use goes up because of the larger size, greater number of electrical gadgets, and farther travel distances. More generally, this tendency for increases in efficiency to lead to greater energy use is called the Jevons Paradox. ${ }^{2}$ These trends are illustrated in Fig. 1. House size increased slowly through the 1980's and then more rapidly in the 1990's and 2000's. Because housing codes and building practices generally improved the efficiency of houses with time, the energy use per square foot steadily declined. From the 1970's to the 1980's, total household energy use actually declined a little, but the greater increase in house size in recent years caused household energy use to increase.

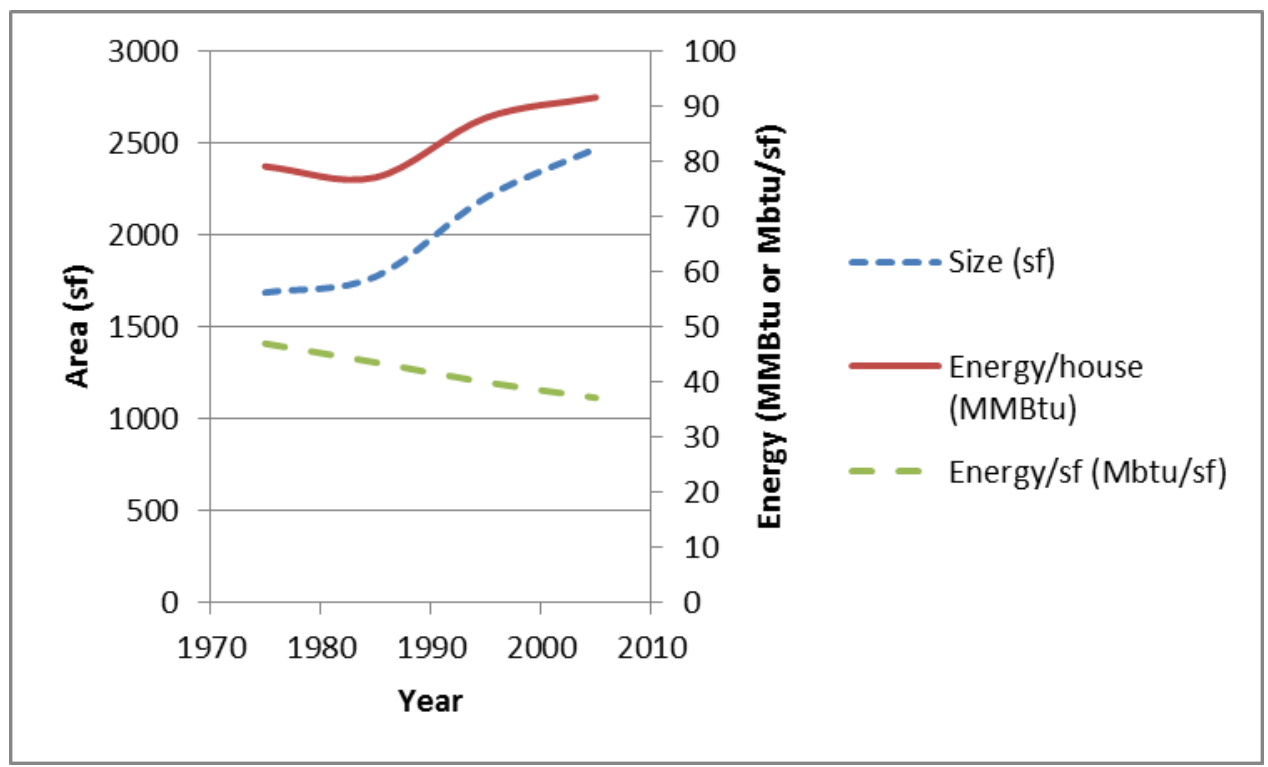

Figure 1 Trends in U.S. house size.

Another issue that is largely neglected in considering new technologies such as solar photovoltaic modules, is Life Cycle Assessment (LCA). While LCA is largely neglected for most technologies, as we begin to design for sustainability it is important that LCA is used to 
understand the environmental and health impacts of alternatives. A complete LCA would investigate these impacts from cradle to cradle, or in other words, from raw materials through making, use and reclamation of the materials at the end of life for use in new products.

In the case of the ZEH project, we observed students designing very large houses with very large solar electric arrays, and little to no attention to conservation or behavioral changes. That was the main motive for introducing costs and a budget into the project. Now that we've made good progress in that area, we're working on further extending the scope of the project as discussed at the end of the paper.

\section{House Economics}

It is typical when considering the extra up-front costs associated with building design options such as more insulation, better windows, and higher efficiency HVAC systems, to also estimate the savings in operating costs. Then some sort of engineering economic analysis is done to inform the decision making. This can range in complexity from simple payback to a more complete life-cycle cost analysis (LCA). For first-year students, simple payback is often the preferred option because it does not involve discount factors, loan payments, tax effects, maintenance, etc. For example, students learn how to estimate all of the operating costs associated with the clothes washing system - hot water energy, motor energy, dryer energy, water cost and sewer cost - to help inform the choice of a clothes washer using simple payback. But for the whole house in this project it is even simpler than that, but more progressive in its effect on reducing energy use overall.

By requiring the students’ designs to be net zero energy (NZE), a hybrid sort of economic analysis happens. Recall that the students are provided a budget that they cannot exceed; in the Fall 2012 semester it was $\$ 250,000$. This includes all of the construction costs, excluding land, and the major equipment purchases including solar water heating, HVAC, and photovoltaic system. If they add attic insulation for example, it will cost more for the insulation. The added insulation will reduce the heating and cooling energy use which will affect the first cost by reducing the size of the PV system to achieve NZE. If the net first-cost effect of higher insulation cost and lesser PV system cost reduces the net cost, then the extra insulation is chosen.

Done this way there is no need to look at operating costs. In fact, if energy cost is the only operating cost considered, it is zero for a NZEH! It does ignore other ongoing costs such as maintenance, insurance, taxes, etc, but for first-year students it is appropriate.

Another way of looking at it is that the students are including the cost of providing the energy for their home in addition to the home's construction cost. Of course the utility still has to have the capacity to meet the home's load when the sun isn't sufficient. Yet even that load is likely to be less than if providing solar electricity was not considered in the project budget. This is because the house will use less energy thanks to the better insulation, tighter construction, and more efficient appliances.

In a conventional home, the marginal cost of providing the electricity to that home is not a consideration of the homeowner or the builder. If electricity cost is considered at all, it might be to look at simple payback or a more complex cash-flow analysis that compares extra up-front 
costs with operating cost savings over time. Most just build a home to meet the minimum standards established by building codes. From an energy use perspective, most houses are the worst house that is legal. While code requirements have steadily improved with regard to reducing energy use, if size did not also increase, they are generally not based on any consistent economic standard such as minimum life-cycle cost over the building's expected lifetime.

\section{Effective Cost of Solar Electricity}

In fall 2012 semester, the solar electric system was assumed to cost $\$ 6.00$ per installed Watt of rated peak array output. This value is just $5 \%$ over the reported national average cost of $\$ 5.71 / \mathrm{Wp}$ in 2011 . $^{3}$ For the sake of this project, this upfront cost is all that is considered. This is incomplete because of several costs during the life of the system that are ignored. These include costs of regular maintenance, insurance, property taxes, and financing, as well as the time value of money. Furthermore, the inverter, the device that converts the direct current electricity from the solar array to alternating current synchronized with the utility, is typically replaced every 10 years. ${ }^{4}$ The solar panels themselves may last up to 50 years, with some loss of output, typically $0.5 \%$ per year. ${ }^{4}$

One of the ways to include all of these factors is to determine the Levelized Cost of Energy (LCOE), which is the Net Present Value of all of the costs associated with the solar electric system divided by the total electricity produced over a chosen lifetime of analysis.

LCOE $(\$ / \mathrm{kWh})=$ Total Life Cycle Cost $(\$) /$ Total Lifetime Energy Production (kWh)

While not used in the project this past fall semester, for the sake of this report this is a useful number because it allows a comparison of the cost of electricity produced by the solar electric system with the utility cost of electricity.

Using the Solar Advisor Module developed by the National Renewable Energy Laboratory for this kind of analysis, an LCOE was determined of \$0.131/kwh with the 30\% federal tax credit, and $\$ 0.235 / \mathrm{kwh}$ without incentives. The assumptions used in the analysis are in Table 1.

Table 1 Parameters used in finding LCOE.

\begin{tabular}{|l|l|}
\hline Location & Harrisburg, PA \\
\hline System Size & $4.0 \mathrm{~kW}$ \\
\hline Tilt \& Orientation & $20^{\circ} \& 180^{\circ}$ (south) \\
\hline System Derating & 0.77 \\
\hline Output Decrease & $0.5 \% / \mathrm{y}$ \\
\hline Installed Cost & $\$ 5.71 / \mathrm{Wp}$ \\
\hline Financing & $30 \mathrm{y}, 10 \%$ down, $4 \%$ interest \\
\hline Maintenance & $\$ 20 / \mathrm{kw}-\mathrm{y}$ and $\$ 1,000$ for inverter replacement in years 10 and 20 \\
\hline Lifetime of Analysis & $30 \mathrm{y}$ \\
\hline Nominal Discount Rate & $8.65 \%(6.00 \%$ real $+2.50 \%$ inflation \\
\hline
\end{tabular}


The local electric utility cost in Harrisburg is currently $\$ 0.126 / \mathrm{kwh}$. With the $30 \%$ federal credit, the LCOE of $\$ 0.131 / \mathrm{kwh}$ is only $4.0 \%$ greater based on the assumptions used in this analysis. Without the credit, the LCOE of $\$ 0.235 / \mathrm{kwh}$ is $79 \%$ greater. This shows the large effect of the federal tax credit on lifetime cost of the system.

Now consider that by having the students constrained to a NZEH, they must include a solar electric system that is sized to provide the annual electricity use of the house. The only cost considered is the installed cost, not any of the other costs considered in determining the LCOE as described previously. To compare this simplified approach to the more correct LCOE, we can calculate a Simplified Cost of Energy (SCOE) by dividing the installed cost by the lifetime electricity produced. Assuming the same 30 year life, a cost of $\$ 5.71 / \mathrm{Wp}$, and the same solar parameters for Harrisburg, SCOE equals $\$ 0.162 / \mathrm{kwh}$. Compare this to the LCOE of $\$ 0.131 / \mathrm{kwh}$ with the $30 \%$ tax credit. In effect, by using the SCOE we are overestimating the cost of solar electricity by $24 \%$. Without the tax credit, SCOE underestimates the LCOE of $\$ 0.235 / \mathrm{kwh}$ by $31 \%$. Figure 2 shows a comparison of the various costs.

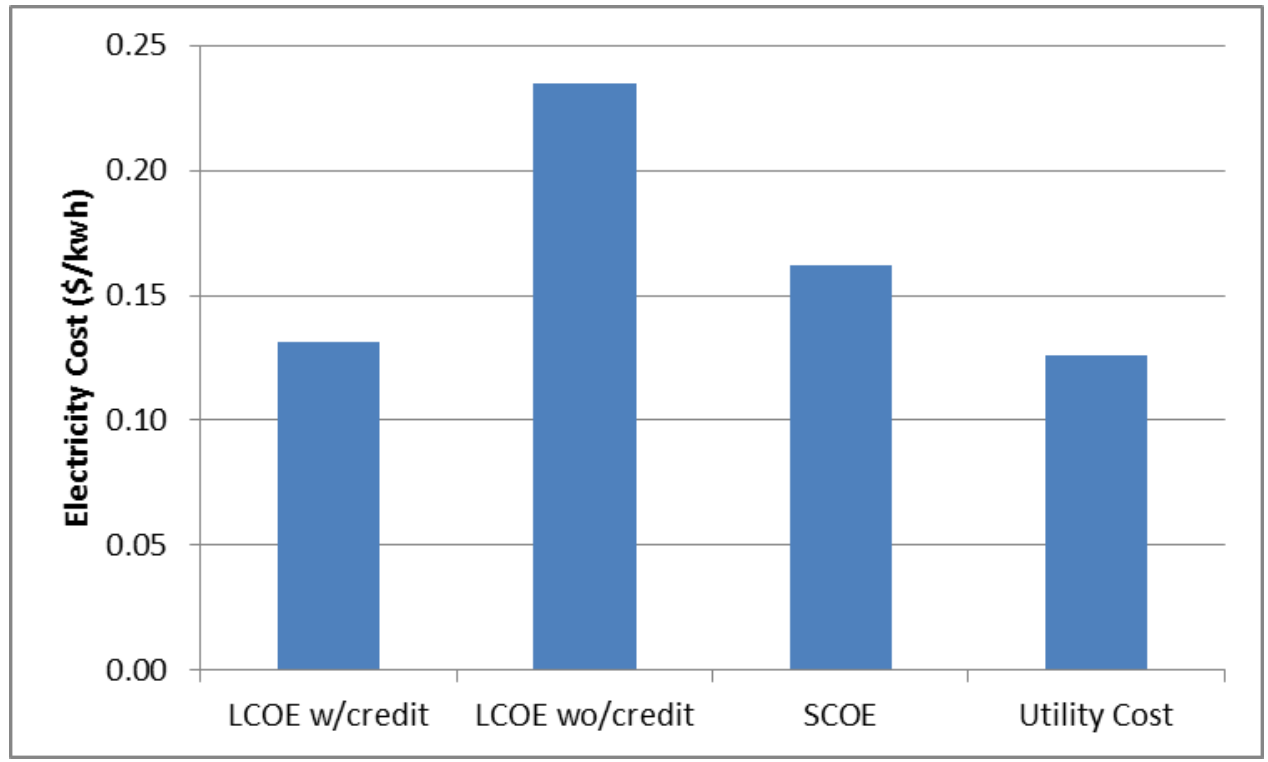

Figure 2 Summary of costs of PV and utility electricity.

Given the additional time needed in the course to prepare students to understand and assess LCOE, and given that SCOE is close to LCOE, it seems like it is a reasonable approach to use SCOE. With the current tax credits, the SCOE overestimates the LCOE and results in designs that are less energy efficient than what would be justified using LCOE.

On the other hand, the fact that the SCOE ( $\$ 0.131 / \mathrm{kwh})$ is greater than the utility cost for Harrisburg (\$0.126/kwh), the NZEH that students design will be more energy efficient than one designed based on electric utility costs over the 30-year lifetime of analysis (assuming no significant electricity cost escalation).

Note that what we really use is the installed cost so that all cost tradeoffs are based on the installed cost of whatever is being considered. Using the installed cost for items that are 
maintenance free or long lived, like insulation and windows, is reasonably accurate. However, for items like heat pumps that will likely require replacement within the 30-year life of analysis, using only installed cost will underestimate their life cycle cost.

\section{Estimating House Construction Cost}

The basic approach to estimating the house construction cost was to use the RSMeans Catalogue for Residential Cost Data. ${ }^{5}$ There are several important options that were defined to provide students with a reasonable range of choices but manageable enough to incorporate into the spreadsheet. These options included:

- House conditioned floor area

- Number of stories: 1, 1.5, 2

- Wall construction

- Attic insulation

- Window U-factor

- Air tightness and Ventilation Air Heat Recovery
- Garage type

- Pool size, if any

- Hot tub size, if any

- HVAC system type

- Solar water heater

- Photovoltaic system size

Furthermore, a house with wood siding was determined to be the standard. Then the cost of an average house was determined for various conditioned floor areas and the three options for number of stories, and these values were used to find a regression equation that best fit the data (Figure 3). It was found that a linear fit worked well for each case, and these equations were incorporated into the spreadsheet.

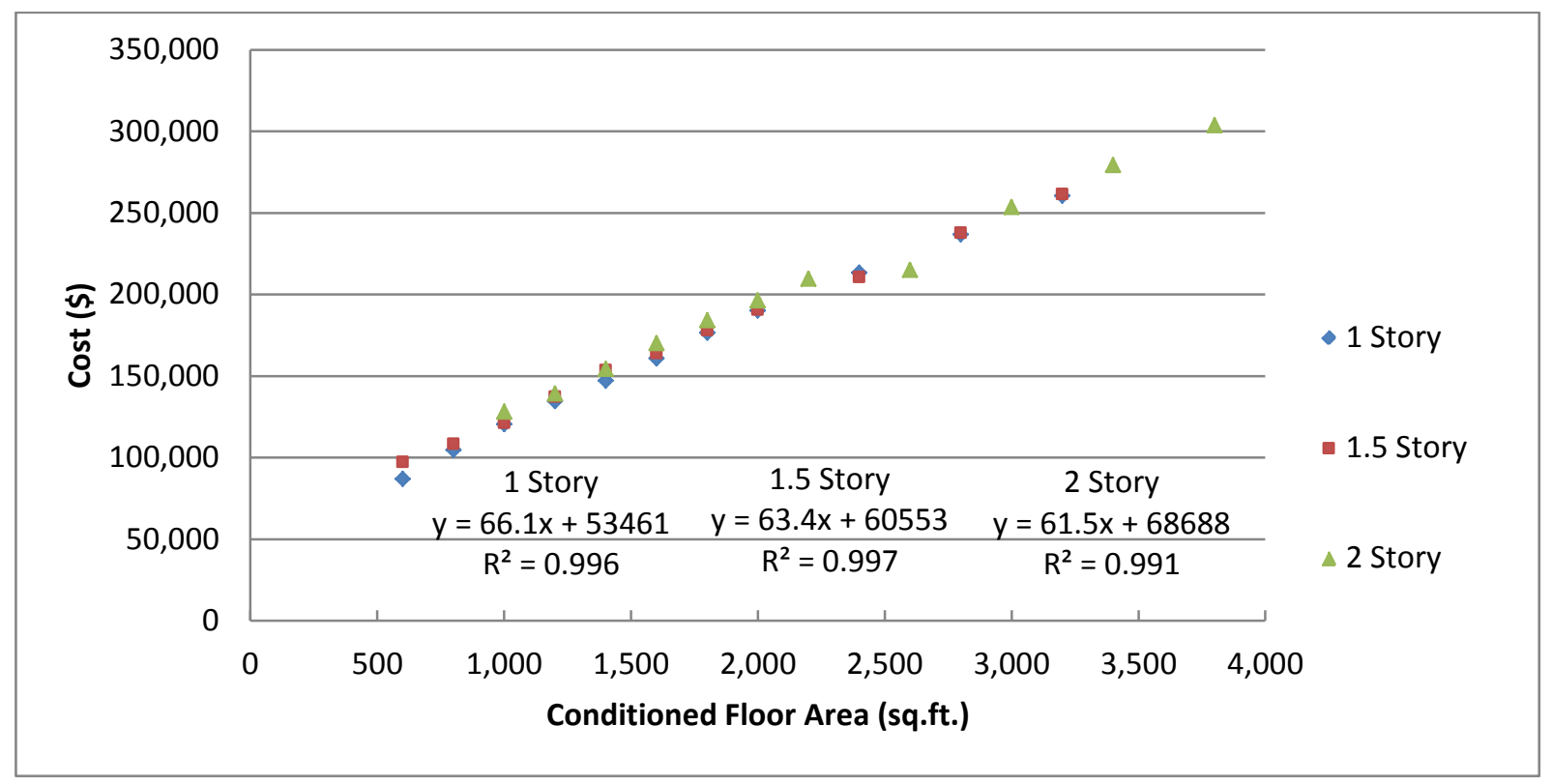

Figure 3 Effect of house size on cost.

With these base house costs, the next step was to quantify the cost of all of the options of each variable within the existing spreadsheet as seen in Table 2. 
Table 2 Various options analyzed for cost.

\begin{tabular}{|l|l|l|l|l|}
\hline Variable & Option 1 & Option 2 & Option 3 & Option 4 \\
\hline Wall Insulation & $\begin{array}{l}\text { 2x4, } \\
\text { R13+1’Foam }\end{array}$ & 2x6, R19 & $\begin{array}{l}\text { 2x6, R19+1” } \\
\text { Foam }\end{array}$ & $\begin{array}{l}\text { Double 2x4, 10” } \\
\text { Foam }\end{array}$ \\
\hline Attic Insulation & R 40 & R 50 & R 60 & \\
\hline Windows & U 0.33; R 3.0 & U 0.25; R 4.0 & U 0.18; R 5.5 & \\
\hline $\begin{array}{l}\text { Solar Water } \\
\text { Heater }\end{array}$ & Yes & No & & \\
\hline HVAC & $\begin{array}{l}\text { Electric } \\
\text { Resistance }\end{array}$ & Heat Pump & $\begin{array}{l}\text { High Efficiency } \\
\text { Heat Pump }\end{array}$ & $\begin{array}{l}\text { Geothermal Heat } \\
\text { Pump }\end{array}$ \\
\hline $\begin{array}{l}\text { Large } \\
\text { Appliances }\end{array}$ & Refrigerator & Washer/Dryer & Range & \\
\hline $\begin{array}{l}\text { Small } \\
\text { Appliances }\end{array}$ & Selected from a list to determine Miscellaneous Electric Load \\
\hline \begin{tabular}{l} 
PV System \\
\hline
\end{tabular} & Offsets the electric usage of the house \\
\hline
\end{tabular}

Wall insulation had three construction options, 2x4, 2x6, and double $2 \times 4$. The walls were dissected into two parts using the RSMeans Residential Cost Data catalogue: the exterior framing component and the insulation component. The framing component in RS Means included lumber, fasteners, and plywood sheathing, so additional cost for lumber and fasteners was added to the double $2 \times 4$ construction. The insulation costing was straight forward. The base price was created for the initial $2 \times 4$ construction with R13 insulation; however that was not up to code standards so it is not included for the students to use. Additional costs of better insulation and variable construction were added to the upgrade costs. The square foot costs used for wall construction and insulation were $\$ 3.53$, \$4.61, $\$ 4.16$, \$5.24, and $\$ 6.59$ for $2 \times 4$ with R13 batt; 2x4 with R13 batt +1" foam; 2x6 with R19 batt; 2x6 with R19 batt +1 ” foam; and Double 2x4 with 10 " foam respectively.

The base cost of attic insulation was assumed to be R40 insulation, the difference between installing R 40 and whatever upgrade was desired was added to the cost of upgrades for the house. Each of these values came from RSMeans and was double checked against home improvement store websites like Lowes and Home Depot. The costs used for attic insulation were \$1.30, \$1.64, and \$2.04 per square foot for R 40, R 50, and R 60 respectively.

Windows were not obtained from the RSMeans catalogue alone, as there is no designation for $\mathrm{U}$ or R factors. For this model, a standard 3' $\mathrm{x}$ 4' double-hung wood-framed window was assumed to be standard. Window manufacturers were contacted for price estimates on windows with similar characteristics as in the spreadsheet. Two local suppliers were reached who gave varying costs for their windows. The costs were averaged out between manufacturers in order to determine the cost additions for a higher $\mathrm{R}$ value. This was then averaged out on a square foot basis for the windows desired in the student's houses. The base window costs per square foot for Double Low E, Super Double Low E, and Triple Low E equivalent efficiencies were \$43.92, \$47.25, and $\$ 57.02$ respectively. Since the base cost of the houses includes some window, in order to simplify the model and keep a reasonable cost estimate, $\$ 43.92 /$ S.F. was removed from each 
option as a base cost for windows, but an additional framing cost of \$8.67/S.F (based on RS Means) was added for houses with more than $12 \%$ of the floor area as windows.

There are three air tightness options in the spreadsheet: average, tight, and tight with ventilation air heat recovery (VAHR). Average is considered the baseline at 0.50 air changes per hour. This number is based on our experience with energy codes and measured air leakage rates in new homes. Tight is equivalent to 0.30 air changes per hour which requires extra air sealing treatment during construction. The extra cost of these measures was $\$ 770$ based on a recent Energy Star Homes survey. ${ }^{7}$ Adding a VAHR system is assumed to reduce the effective infiltration rate to 0.05 air changes per hour at an additional estimated cost of $\$ 1,500$.

Solar water heater data was acquired from the RSMeans Residential and Green Building Cost Data, as well as from calling several local and national contractors for costing estimates. ${ }^{6}$ Using an aggregate of all sources and engineering judgment, three costs were created, one for a two bedroom, a three bedroom, and a four bedroom home. This was the most robust way to properly calculate the size and cost of the system in this model.

The HVAC system was by far the most challenging aspect of the costing project, as the size of the system changes the cost in different ways for each system option. RSMeans did not have the adequate data for this piece of the project, so instead internet research using a variety of retailers was used for a baseline on system costs. Additionally, several local contractors were consulted to learn about material costs, installation costs, efficiencies, and greatest value of a system. On average, contractors tend to charge as much for installation as for equipment and materials. Given product data from manufacturers, a linear regression was used in order to simplify the process and achieve prices for various house sizes and loads. Figure 2 shows the data and relationships that were determined and used in the spreadsheet.

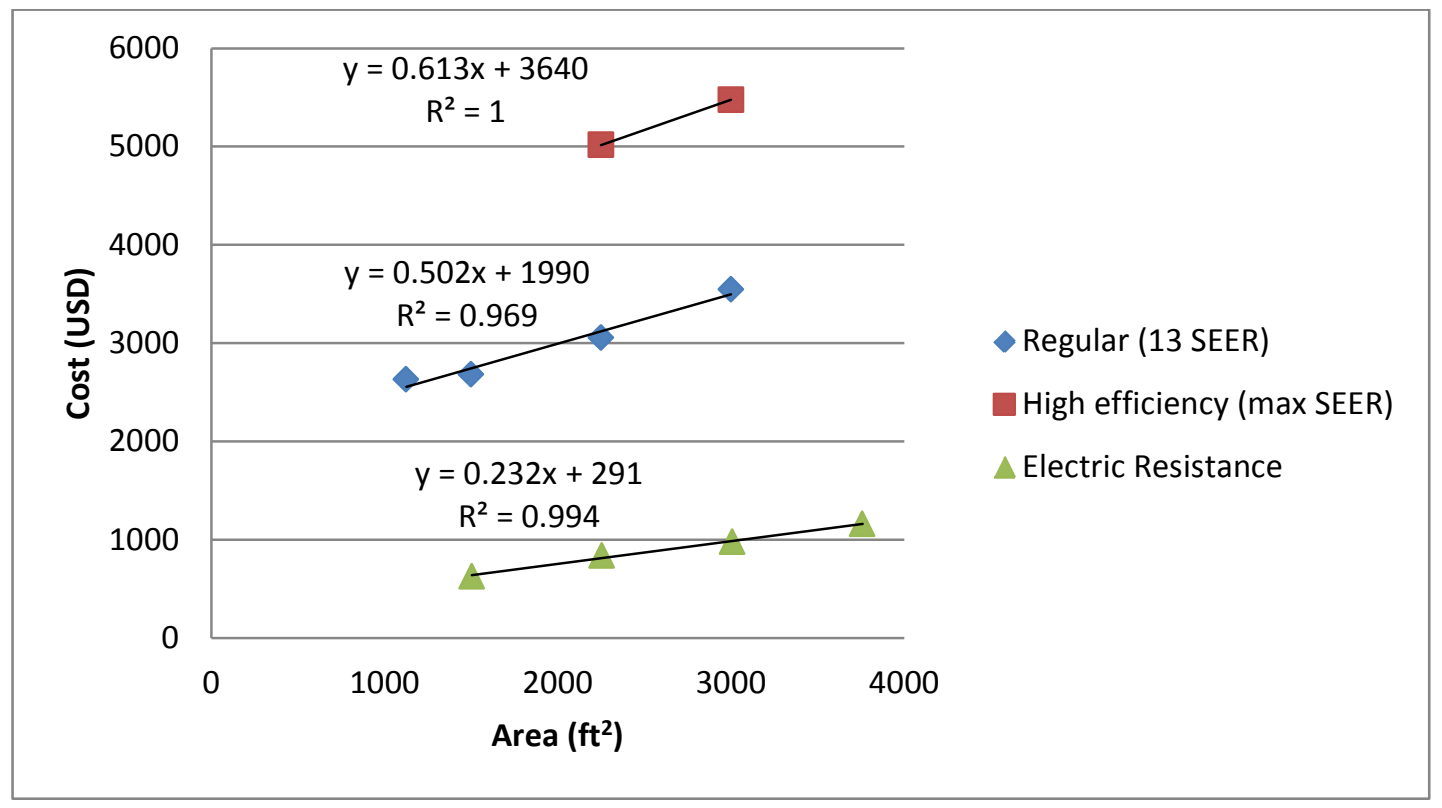

Figure 4 Relative costs of various HVAC options. 
Electric resistance baseboard was the least expensive and most linear of the options. One issue which was encountered was that smaller heat pump units tend not to be made for efficiency, hence the lack of lower range data for high efficiency units. This was an interesting problem, as generally the ones who care most about increasing efficiency of their products, are the ones who use less in the first place. In general, it was found that geothermal systems can be rivaled in efficiency by high efficiency heat pumps (HEHP), but tend to be more costly. Geothermal systems were assumed to scale the same way as HEHP, but with a higher upfront cost based on conversations with contractors. Overall, each of the regressions from Figure 4 were multiplied by two to factor installation costs and used in the model.

Appliances turned out to be a lot less intuitive than expected. It was expected that the more energy efficient an appliance was, the more expensive it would be, but that turned out to have very little to do with the cost of the appliance. From browsing through hundreds of manufacturer and retailer webpages and speaking with several salesmen, it was determined that the most important factors in cost of major appliances were extra features, finishes, and color. For this reason it was decided not to include costs for the upgrade of appliances, but instead to stress this fact to the students that when purchasing appliances, they ought to seek the most efficient, as it would not cost them anything extra.

Small appliances were previously counted as a miscellaneous electric load, which referenced an average load from the Building America study of American households. ${ }^{8}$ This was used as a base point for students to pick out what appliances they would want in their house, and price them accordingly. While this was not added into the total cost of the house, it was used to indicate to students that the more appliances they have, the more they will pay for it both up front, and in the long term.

The PV system was scoped out based on speaking with various contractors, and solar installation manufacturers. Most online solar cost estimators use a value of \$7/watt. From speaking with customer service representatives at one of these websites, it was discovered that most contractors tend to charge around \$5/watt. An average of \$6/watt was used for this model. As mentioned earlier, this value is very close to the average costs for 2011.

\section{A Study of Design Options and Their Impact on Cost}

To investigate the relative impacts of the many design options on the total house cost, a base case house was defined from a compact house design found on the internet. The house is pictured in Figure 5, and was used as the basis for the design except for the addition of two additional windows on the front side which was oriented south for good passive solar gain. It is a small house that is representative of providing a three-bedroom, two bath house all within a conditioned floor area of only 1,100 square feet. The house was analyzed for Philadelphia, Pennsylvania. 


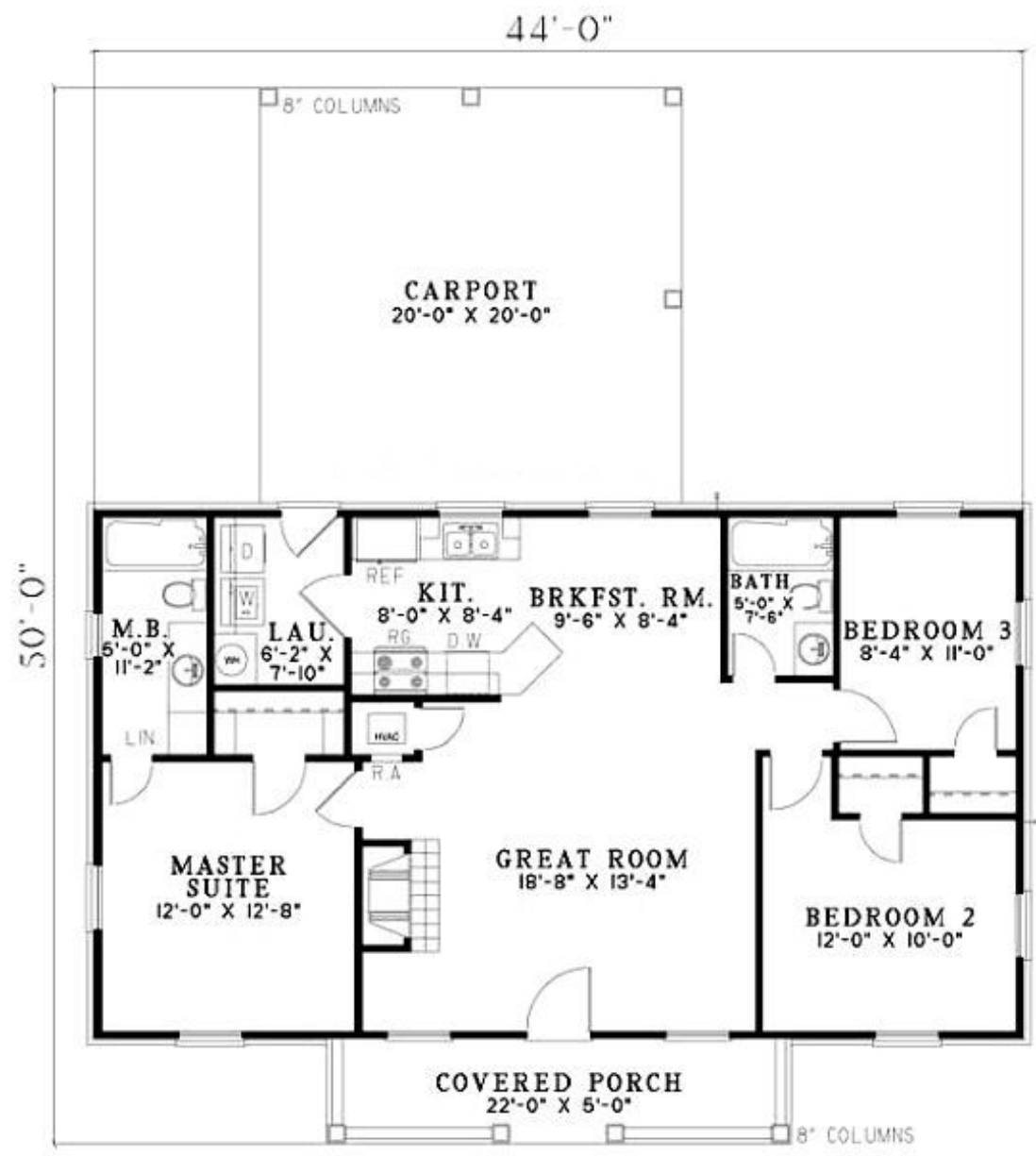

Figure 5 Floor plan of a small house used for cost analysis.

The house characteristics were all set at the minimum levels that meet code to begin the investigation. An exception was the HVAC system which was set to be a standard efficiency heat pump. Then incremental changes were made starting with behavioral changes and then moving through the options in the order listed in Figure 6. Before moving on to the next feature, the current characteristic was set to the level that resulted in the lowest cost. These lowest-cost features are indicated by an asterisk. 


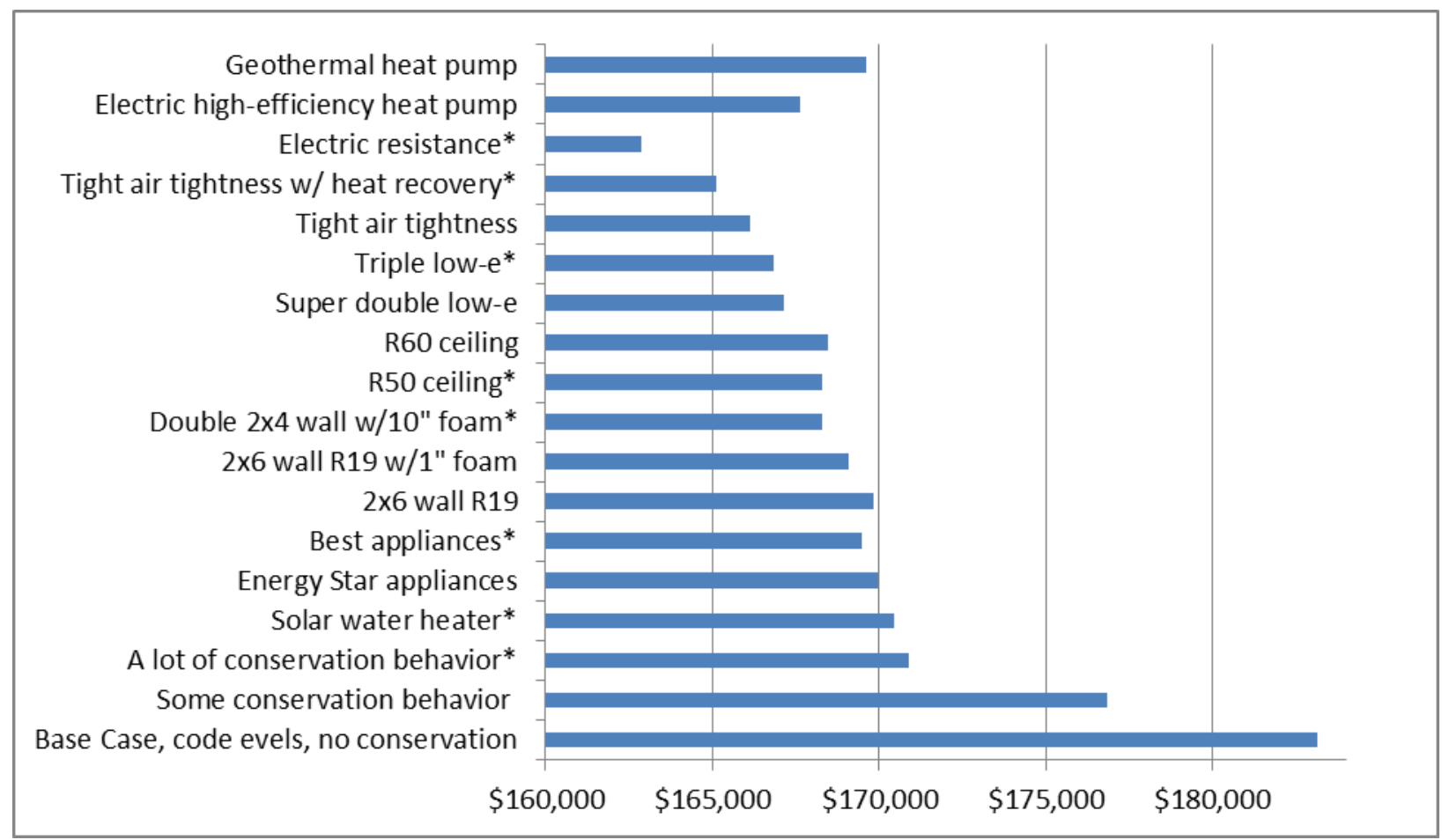

Figure 6 Cost comparison of various design options.

There are several insights to be learned from this study. First is that behavioral changes made the most difference in the first cost of the house. The changes had no added cost to implement, but had a great impact on the energy use and the resultant size of the photovoltaic system and its cost. There were three behaviors lumped together: water conservation, use of a clothes line, and use of thermostat setback. This is an important lesson for students.

All but two design features resulted in the lowest cost with the highest efficiency option. For the majority of the options, the added cost of the highest efficiency option was more than offset by a reduction in the size of the photovoltaic system and its lower cost. The only two features that resulted in a lower net cost at a less efficient level were attic insulation at R50, and the HVAC system at electric resistance. For the attic insulation, the highest level of R60 increased the net first cost of the house.

The HVAC system options, in order from lowest to highest efficiency, are electric resistance, high efficiency (air source) heat pump, and geothermal heat pump. Note that the term "geothermal heat pump" is now used more commonly than the more correct "ground-source heat pump.” While the higher efficiency systems reduce the home energy use and the resultant photovoltaic system size, their added cost is greater than the savings from the smaller photovoltaic size. This result is related to that fact that this measure was investigated last so that the home was already using less energy from all of the other measures.

Experiences Using a Cost Constraint in the First-Year Project 
As mentioned previously, costs were developed for this design project to provide a realistic constraint on the design tradeoffs, particularly size. After we developed the cost data described in this report, we considered just what the design budget should be. We chose $\$ 250,000$ based on some estimates that showed that students could still design homes of reasonable size but slightly smaller than the average new home today, approximately 2,000 square feet. In this way, the students could develop designs that reflected their aspirations and experiences with their family's homes. Table 3 is a summary of their final design characteristics.

Table 3 Summary of student ZEH designs from Fall 2012.

\begin{tabular}{|l|c|c|c|}
\hline \multicolumn{1}{|c|}{ Team } & $\begin{array}{c}\text { Floor } \\
\text { area (sf) }\end{array}$ & $\begin{array}{c}\text { PV size } \\
(\mathrm{kw})\end{array}$ & $\begin{array}{c}\text { Cost } \\
(\$)\end{array}$ \\
\hline Alpha & 1984 & 6.96 & 244,000 \\
\hline BBAM & 1903 & 5.85 & 249,000 \\
\hline Lau's Cows & 1840 & 6.36 & 249,000 \\
\hline LikeABoss & 1456 & 6.51 & 240,000 \\
\hline SealTeam8 & 1908 & 4.96 & 246,000 \\
\hline VMAK & 1780 & 6.55 & 245,000 \\
\hline WolfPack & 1734 & 6.75 & 249,000 \\
\hline WST & 1792 & 8.64 & 229,000 \\
\hline
\end{tabular}

The students made models of their homes using Google SketchUp and they also made scale models, 1/8"=1'0”, using chipboard. Figure 7 is a photo of their chipboard models assembled into a small village. The small scale was chosen to be easy to store in the shop and also to be compatible with an $\mathrm{HO}$ scale model railroad. We may in the future take the several sections that use this project and make a larger village with a train for display in the engineering lounge area.

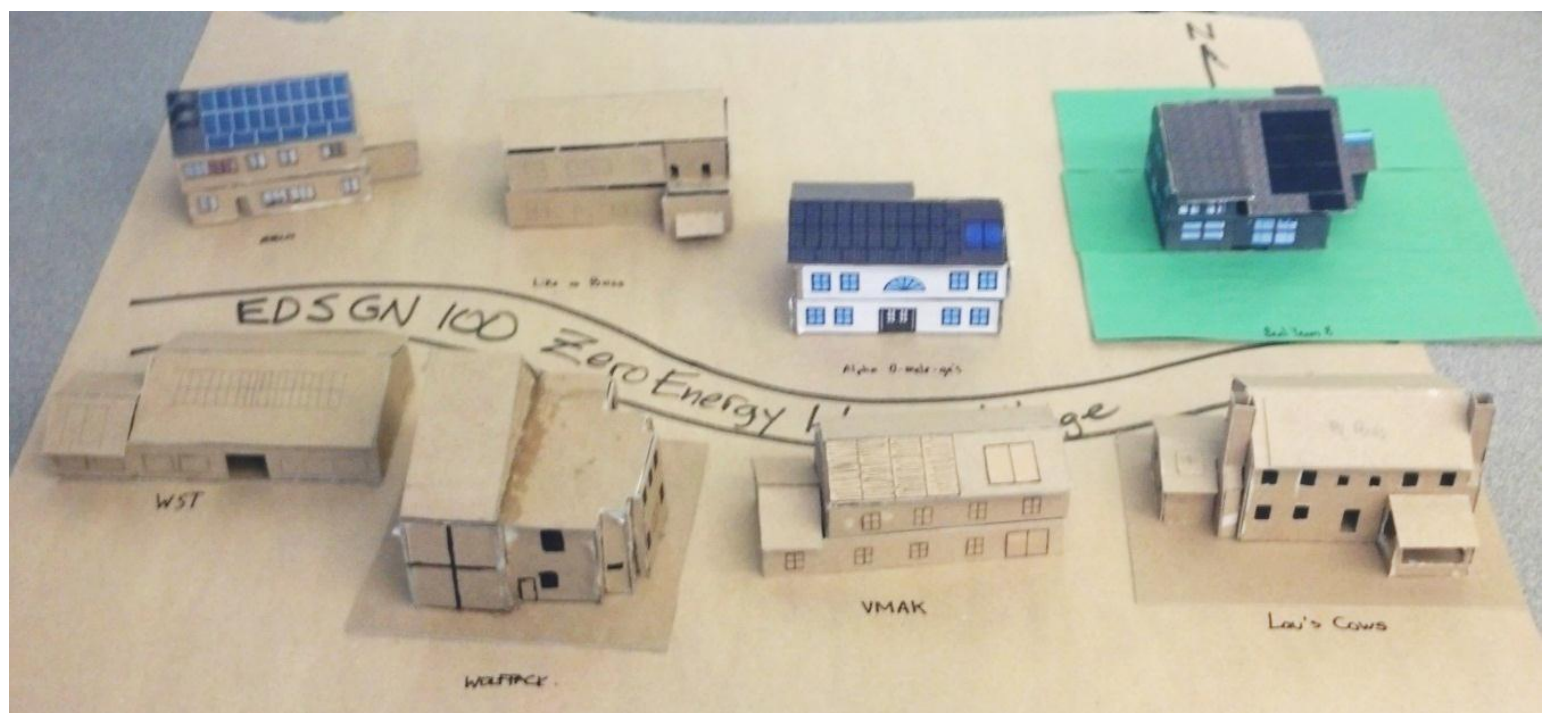

Figure 7 Scale models of students' ZEH designs from Fall 2012. 
The following quotes were taken from the conclusions sections of the student teams' final reports. They were asked to reflect on what they had learned from this project.

Lastly, and perhaps most importantly, our team learned that it is possible to build a comfortable, zero energy home at a reasonable price. Simply through thorough and in depth research, we were able to design a house model that is financially accessible to the middle class, not just the wealthy. The implications of this finding is quite significant, as it implies that a vast portion of citizens have the potential to greatly minimalize their ecological footprint and bring us, collectively, closer to sustainability.

This project was relevant to our lives because in our generation more and more people are starting to realize the affect our society's choices have on the environment and future generations. With a growing global population and increased demand for limited resources, the concept of a low impact home becomes even more relevant. Our house design had to consider principles of sustainability because this concept has the power to change the way the society uses its resources.

These necessary design changes helped us to realize that engineers face many limits in their designs, including availability of resources and budget. In addition, the necessity to make design changes made it clear to us that engineering design is not a one solution process. It requires a great deal of patience and an open mind, something we quickly learned when we had to think of how to effectively alter the house's design without compromising the most desired features of the home.

These quotes indicate that overall the project serves to increase their understanding of sustainability in engineering design. Furthermore, the added budget constraint forced them to make tradeoffs and to prioritize design elements to arrive at a the best design within the budget.

\section{Future Plans}

There are two changes already bring implemented this spring semester. One is to further reduce the budget to $\$ 185,000$ with emphasis on designing affordable homes that are within reach of lower middle class families. Based on some preliminary analysis, this will constrain the house size to close to 1,200 square feet. We have found many compact home designs on the internet that manage to fit three bedrooms into this size. One of the author's first homes was a ranch house built in the 1950's that had only 950 square feet and three bedrooms. Home affordability is a pressing in many parts of the country and world. Students will be tasked to investigate the needs of lower income families to help define their design objectives.

A more important change is to broaden the scope of the project to include looking at the other systems that are connected to the home, in particular sewage treatment and electricity production. We also intend to include transportation and food production. Besides the obvious benefit of examining the bigger picture, this will also provide opportunities for students to do investigations about technologies and innovations that are more relevant to their intended majors. For example, sewage treatment will relate to civil and environmental, as well as chemical and 
biological engineering. Electricity production will also be relevant to chemical and electrical engineering. And food production will be especially relevant to agricultural engineering.

\section{Conclusions}

Cost considerations and a project budget were successfully integrated into a comprehensive design project for first-year engineering students. These additions required students to further consider design options and tradeoffs in their conceptual designs, resulting in a more realistic and relevant experience of engineering design. While the approach of using only first costs in this process is not as robust as a more comprehensive life-cycle cost analysis, the first cost chosen for the solar electric system is close to one derived using life-cycle costs.

\section{References}

1. Sulewski, A. L. (2012). Design of a Zero-Energy Home as a First Year Design Project. American Society for Engineering Education Annual Meeting. San Antonio, TX.

2. Jevons, W. S. (1866). The Coal Question. London: MacMillan and Co.

3. Woodhouse, M., An Economic Analysis of Photovoltaic Versus Traditional Energy Sources: Where Are We Now and Where Might We Be in the Near Future. IEEE Photovoltaic Specialists Conference (PVSC). Seattle, WA., 2011.

4. Paul Denholm, R. M.,. Break-Even Cost for Residential Photovoltaics in the United States: Key Drivers and Sensitivities. Golden, CO: National Renewable Energy Laboratory, NREL/TP-6A246909, 2009.

5. Bob Mewis, et al, Editors, Residential cost data 2012, R.S. Means Company, Norwell, MA, 2011.

6. R.S. Means Company, \& Reed Construction Data, Green building cost data. Reed Construction Data Inc., Norwell, MA, 2011.

7. ENERGY STAR Qualified Homes 2011 Savings \& Cost Estimate Summary, Downloaded from http://www.energystar.gov/ia/partners/bldrs_lenders_raters/downloads/Savings_and_Cost_Estimate_Summary.p df, 2011, Downloaded October 18, 2012.

8. Robert Hendron, Building America Research Benchmark Definition, National Renewable Energy Laboratory, Golden, Co, Updated December 15, 2006. 